03

\title{
Дифракция света на ультразвуке в пространственно периодическом акустическом поле
}

\author{
(C) В.И. Балакший, М.И. Купрейчик, С.Н. Манцевич \\ Московский государственный университет имени М.В. Ломоносова, физический факультет \\ 119991 Москва, Россия \\ e-mail: balakshy@phys.msu.ru
}

Поступила в редакцию 25.03.2019 г.

В окончательной редакции 25.05.2019 г.

Принята к публикации 04.06.2019 г.

\begin{abstract}
Теоретически исследованы особенности анизотропной дифракции света в пространственно периодическом акустическом поле, создаваемом секционированным пьезопреобразователем с противофазным возбуждением соседних секций. Численный расчет выполнен для ячейки из кристалла парателлурита со сдвиговой акустической модой, распространяющейся под углом $3^{\circ}$ к плоскости $(001)$ кристалла. Показано, что этот тип акустооптического взаимодействия имеет ряд интересных особенностей, которые могут быть использованы при разработке акустооптических приборов, в частности модуляторов неполяризованного света.
\end{abstract}

Ключевые слова: акустооптическое взаимодействие, анизотропная дифракция, брэгговский синхронизм, фазированные решетки пьезопреобразователей, парателлурит.

DOI: $10.21883 /$ OS.2019.10.48373.126-19

\section{Введение}

В настоящее время в акустооптических (АО) приборах применяется, как правило, режим дифракции света на ультразвуке, близкий к брэгговскому [1-3]. Этот режим наблюдается на достаточно высоких акустических частотах (обычно свыше $100 \mathrm{MHz}$ ) и позволяет создавать устройства с хорошим быстродействием и малыми световыми потерями. Тем не менее как недостаток можно отметить высокую селективность такого варианта взаимодействия - сильную зависимость эффекта от частоты ультразвука, угла падения света и длины волны оптического излучения. Важной характеристикой эффекта является угол Брэгга $\theta_{\mathrm{B}}$. При падении светового пучка под углом Брэгга (условие фазового синхронизма) происходит наиболее эффективное рассеяние света в дифракционный порядок, а уменьшение эффективности дифракции на $3 \mathrm{~dB}$ определяет границу области $\mathrm{AO}$ взаимодействия.

В принципе частотный диапазон взаимодействия $\Delta f$ можно расширить, уменьшив длину АО взаимодействия $L$ (ширину акустического пучка в направлении распространения света), но это приведет к уменьшению эффективности дифракции и/или увеличению акустической мощности, необходимой для получения заданной эффективности дифракции. Именно в этом контексте можно рассматривать работу Корпела с сотр. [4], которые в 1966 г. предложили использовать ступенчатый секционированный пьезопреобразователь для возбуждения акустического пучка с поворачивающейся диаграммой направленности. В разработанной ими АО ячейке при изменении частоты ультразвука акустический волновой фронт поворачивался, подстраиваясь под оптимальный угол падения света.

Однако такая ячейка оказалась весьма сложной в изготовлении, поэтому вскоре была предложена планарная структура, показанная на рис. 1, a [5-8]. Здесь секционированный преобразователь изготовлен из одной пластинки пьезоэлектрика, а секции получаются с помощью пропилов и разделением внешнего электрода. На рисунке показана АО ячейка с преобразователем, содержащим четыре секции, которые соединены электрически последовательно, но таким образом, что направление электрического поля (показанное стрелками) в соседних секциях противоположно. Благодаря этому акустические пучки от каждой секции возбуждаются со сдвигом фазы на $\pi$, и образуется система эквивалентных волновых фронтов (показанных двумя штриховыми прямыми), повернутых на угол $\Psi$ относительно плоскости преобразователя. Угол $\Psi$ определяется выражением

$$
\Psi= \pm \frac{\Lambda}{2 d}= \pm \frac{V}{2 d f},
$$

где $\Lambda=V / f$ - длина акустической волны, $V$ - ее скорость, а $d$ - период решетки преобразователя. По сравнению с однородным преобразователем здесь передаточная функция АО ячейки $T(\theta)$ содержит два основных максимума, располагающихся симметрично относительно угла Брэгга $\theta_{\mathrm{B}}$, как показано на рис. $1, b$ кривой 1. Из рисунка следует, что АО дифракция должна отсутствовать при падении света под углом Брэгга $\left(\theta_{0}=\theta_{\mathrm{B}}\right)$. Это обусловлено тем, что парциальные дифрагированные волны, рождающиеся в соседних акустических пучках, сдвинуты по фазе на $\pi$, и поэтому гасят друг друга при интерференции. Но зато появляются другие максимумы, которые расположены эквидистантно 

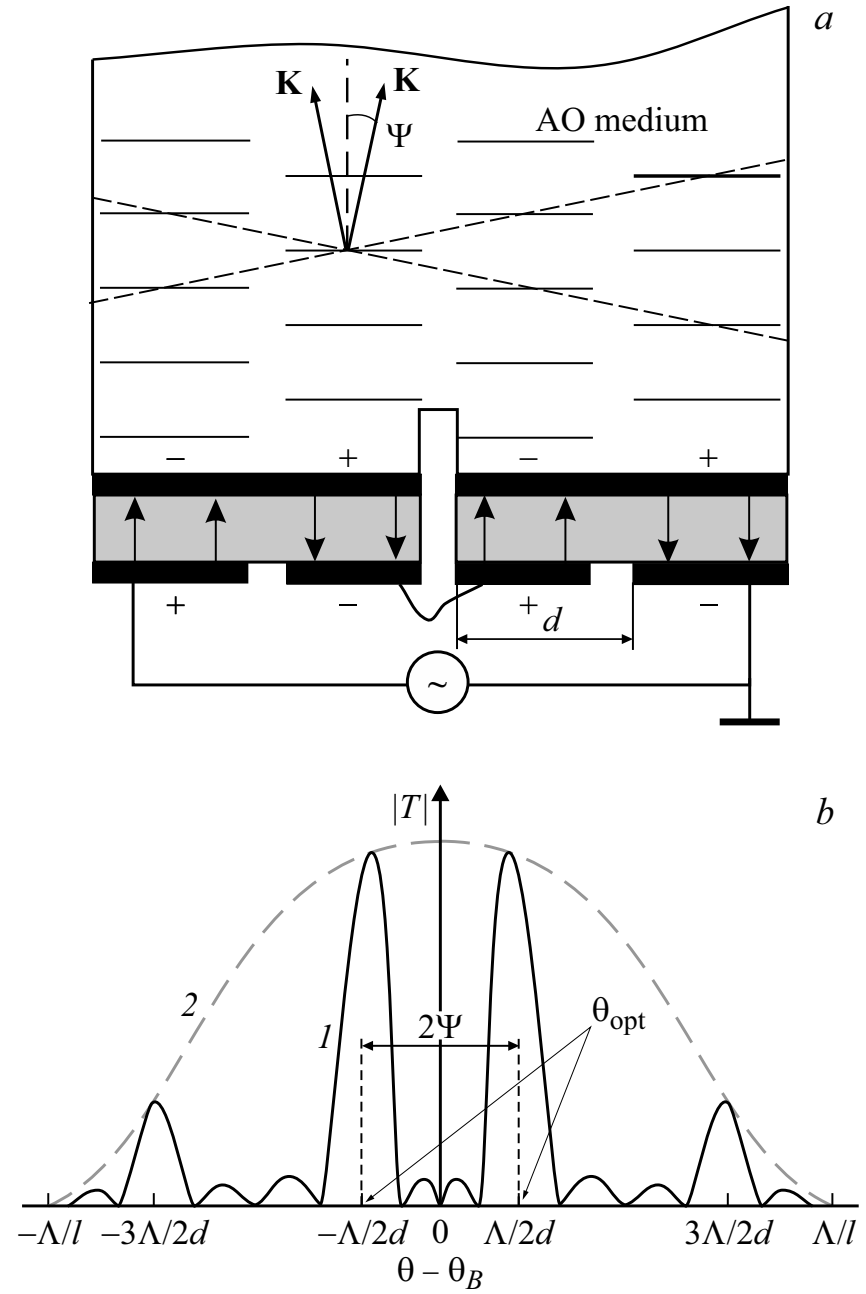

Рис. 1. (a) Один из возможных вариантов конструкции АО ячейки с фазированным пьезопреобразователем. (b) Диаграммы направленности четырехсекционного (1) и односекционного (2) преобразователей.

с периодом $\Lambda / m d$, вписанные в штриховую кривую 2 , которая является диаграммой направленности отдельной секции излучателя. Ширина максимумов равна $\Lambda / m d$, где $m$ - число периодов структуры. Таким образом, само понятие угла Брэгга как угла падения света, при котором выполняется условие фазового синхронизма и наблюдается максимальная эффективность дифракции, оказывается неверным. Здесь можно говорить об оптимальных углах падения света $\theta_{\text {opt }}=\theta_{\mathrm{B}} \pm \Lambda / 2 d$, соответствующих максимуму рассеяния света, хотя условие фазового синхронизма при этом нарушено. Заметим, что эти оптимальные углы падения соответствуют обычным углам Брэгга при падении света на эквивалентные волновые фронты. Следовательно, подобную структуру акустического поля можно рассматривать как суперпозицию двух полей, возбуждаемых двумя сплошными пьезопреобразователями, повернутыми относительно друг друга на угол $\Lambda / d$. Наши расчеты показали, что при $\theta_{0}=\theta_{\text {opt }}$ эффективность дифракции может дости- гать $100 \%$, несмотря на заметную фазовую расстройку. Но для этого требуется несколько большая акустическая мощность $[9,10]$.

Как следует из (1), при уменьшении частоты ультразвука основные лепестки диаграммы направленности преобразователя расходятся. Поэтому если правильно выбрать угол падения света, то эквивалентный волновой фронт будет поворачиваться, подстраиваясь под меняющийся угол Брэгга. Такая подстройка не будет полной, поскольку угол Брэгга зависит от частоты линейно, а угол поворота $\Psi$ - по гиперболическому закону. Наилучшая коррекция брэгговского угла получается, когда $d \theta_{\mathrm{opt}} / d f=0$. Это условие выполняется на частоте

$$
f_{0}=V \sqrt{\frac{n}{\lambda d}}
$$

где $n$ - показатель преломления АО среды, а $\lambda$ длина волны света в вакууме. Таким образом, выбрав соответствующий период $d$ решетки фазированного преобразователя, можно задать рабочую точку $f_{0}$ в любой желаемой области частот.

Интерес к фазированным преобразователям заметно ослаб, после того как в практику акустооптики вошла анизотропная дифракция, происходящая со сменой оптической моды [11]. Главное достоинство анизотропной дифракции состоит в существенно более сложной частотной зависимости угла Брэгга по сравнению с АО взаимодействием в изотропной среде, что позволяет выбирать оптимальную геометрию взаимодействия для каждого отдельного АО устройства. Так, например, для $\mathrm{AO}$ дефлекторов оптимальной является область, где $d \theta_{\mathrm{B}} / d f \rightarrow 0$, а для $\mathrm{AO}$ видеофильтров - где $d \theta_{\mathrm{B}} / d f \rightarrow \infty[1,2]$. Применение фазированных пьезопреобразователей при анизотропной дифракции приводит к еще более сложному виду брэгговских кривых, что открывает новые возможности для совершенствования $\mathrm{AO}$ приборов [12,13]. Поэтому целью настоящей работы являлось исследование особенностей анизотропного АО взаимодействия в акустическом поле, создаваемом фазированной решеткой преобразователей с противофазным возбуждением соседних элементов.

\section{АО эффект в поле фазированного пьезопреобразователя}

Рисунок 2 иллюстрирует постановку задачи. Рассматривается наиболее общий случай анизотропной среды, в которой акустические пучки распространяются с углом сноса $\alpha$. Предполагается, что наклонная фазовая решетка, создаваемая акустической волной, занимает область пространства между бесконечными плоскостями $x=0$ и $x=L$. Волновой вектор ультразвука наклонен под углом $\alpha$. Ширина каждого акустического столба равна $l$. Поэтому второй столб занимает пространство между плоскостями $x=l+a$ и $x=2 l+a$, где $a-$ зазор между акустическими пучками, ит.д. Начальная 
акустическая фаза в первом столбе равна $\Phi=0$, в следующем - $\Phi=\pi$; таким образом, фазовый сдвиг между соседними пучками равен $\Delta \Phi=\pi$. Общее число пучков равно $m$.

Рассмотрим в представленной структуре режим анизотропной дифракции Брэгга с рассеянием света в два порядка: нулевой и +1-й. В этом случае в расчете необходимо учесть две плоские световые волны. Первая волна является падающей, ей соответствует волновой вектор $\mathbf{k}_{0}$ и угол падения $\theta_{0}$. Второй является дифрагированная волна с волновым вектором $\mathbf{k}_{1}$ и углом дифракции $\theta_{1}$. Взаимодействие волн описывается системой уравнений $[14,15]$

$$
\left\{\begin{array}{l}
\frac{d C_{0}}{d X}=\frac{\Gamma}{2} C_{1} \exp [j(R X-\Phi)] \\
\frac{d C_{1}}{d X}=-\frac{\Gamma}{2} C_{0} \exp [-j(R X-\Phi)]
\end{array},\right.
$$

где для удобства численных расчетов введены безразмерные величины: нормированные амплитуды падающей $C_{0}$ и дифрагированной $C_{1}$ волн, координата $X=x / l$, параметр Рамана-Ната

$$
\Gamma=\frac{2 \pi l \Delta n}{\lambda \cos \theta_{0}}
$$

и безразмерная фазовая расстройка

$$
\begin{aligned}
R= & \frac{2 \pi}{\lambda} l\left[n_{0} \cos \theta_{0}-\frac{\lambda f}{V} \sin \alpha\right. \\
& \left.-\sqrt{n_{1}^{2}-\left(n_{0} \sin \theta_{0}+\frac{\lambda f}{V} \cos \alpha\right)^{2}}\right] .
\end{aligned}
$$

В этих формулах $\lambda$ - длина волны света в вакууме, $f$ и $V$ - частота и скорость акустической волны, $n_{0}$ и $n_{1}-$ показатели преломления для падающего и дифрагированного света, $\Delta n-$ амплитуда изменения показателя преломления под действием акустической волны. На рис. 2 справа изображена диаграмма АО взаимодействия, соответствующая векторному соотношению [1]

$$
\mathbf{k}_{0}+\mathbf{K}+\mathbf{R} / l=\mathbf{k}_{1} \text {. }
$$

Здесь учтено, что вектор фазовой расстройки $\mathbf{R}$ перпендикулярен границам акустических пучков. При распространении световых волн в периодическом акустическом поле происходит перераспределение энергии между ними. Нашей задачей является нахождение амплитуд световых волн на выходе из структуры: $C_{0}(L)$ и $C_{1}(L)$.

Это можно сделать, записав рекуррентное соотношение, связывающее входное и выходное поля для $i$-го акустического пучка. Граничные условия на входе имеют

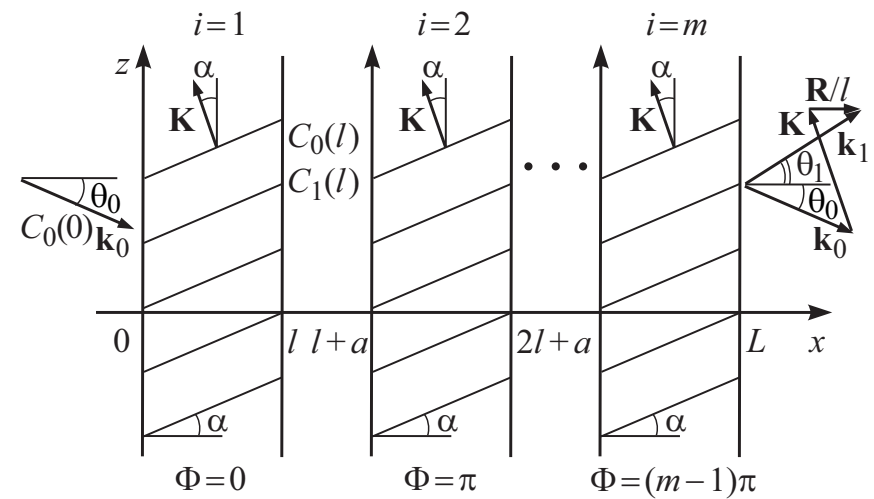

Рис. 2. Постановка задачи АО взаимодействия в поле фазированного пьезопреобразователя.

Вид

$$
\left\{\begin{array}{l}
E_{0}(x)=E_{i} C_{0}^{(i)} \exp \left[j\left(\omega_{0} t-k_{0} \cos \theta_{0} x-k_{0} \sin \theta_{0} z\right)\right] \\
E_{1}(x)=E_{i} C_{1}^{(i)} \exp \left[j\left(\omega_{1} t-k_{1} \cos \theta_{1} x-k_{1} \sin \theta_{1} z\right)\right]
\end{array}\right.
$$

где $E_{i}-$ амплитуда падающей световой волны, $\omega_{0}$ и $\omega_{1}$ - частоты падающего и дифрагированного света, при этом $\omega_{1}=\omega_{0}+\Omega, \Omega=2 \pi f-$ циклическая частота ультразвука. Решая уравнения (3) с граничными условиями (7), получим следующие выражения для амплитуд на входе в $(i+1)$-й акустический столб:

$$
\begin{aligned}
C_{0}^{(i+1)} & =\left[C_{0}^{(i)}\left(\cos \frac{\sqrt{\Gamma^{2}+R^{2}}}{2}-j \frac{R}{2} \operatorname{sinc} \frac{\sqrt{\Gamma^{2}+R^{2}}}{2 \pi}\right)\right. \\
& \left.+C_{1}^{(j)} \frac{\Gamma}{2} \operatorname{sinc} \frac{\sqrt{\Gamma^{2}+R^{2}}}{2 \pi} \exp (-j \Phi)\right] \exp \left(j \frac{R}{2}\right), \\
C_{1}^{(i+1)} & =\left[C_{1}^{(i)}\left(\cos \frac{\sqrt{\Gamma^{2}+R^{2}}}{2}-j \frac{R}{2} \operatorname{sinc} \frac{\sqrt{\Gamma^{2}+R^{2}}}{2 \pi}\right)\right. \\
& \left.-C_{0}^{(j)} \frac{\Gamma}{2} \operatorname{sinc} \frac{\sqrt{\Gamma^{2}+R^{2}}}{2 \pi} \exp (-j \Phi)\right] \exp \left(-j \frac{R}{2}\right) .
\end{aligned}
$$

Здесь учтен фазовый сдвиг, вносимый областью пустого пространства между акустическими столбами [16]:

$$
C_{0}(l+a)=C_{0}(l), \quad C_{1}(l+a)=C_{1}(l) \exp \left[j \frac{R}{l}(l+a)\right] .
$$

При этом одинаковый фазовый сдвиг $\exp \left[-j k_{0} \cos \theta_{0}(l+a)\right]$ опущен.

$\mathrm{B}$ акустооптике углы падения и дифракции принято отсчитывать от фронта акустической волны. В соответствии с этим введем углы $\varphi_{0,1}=\theta_{0,1}-\alpha$. Условие фазового синхронизма $R=0$ определяет угол Брэгга:

$$
\sin \left(\theta_{\mathrm{B}}-\alpha\right) \equiv \sin \varphi_{\mathrm{B}}=-\frac{\lambda f}{2 n_{0} V}\left[1+\frac{V^{2}}{\lambda^{2} f^{2}}\left(n_{0}^{2}-n_{1}^{2}\right)\right] .
$$




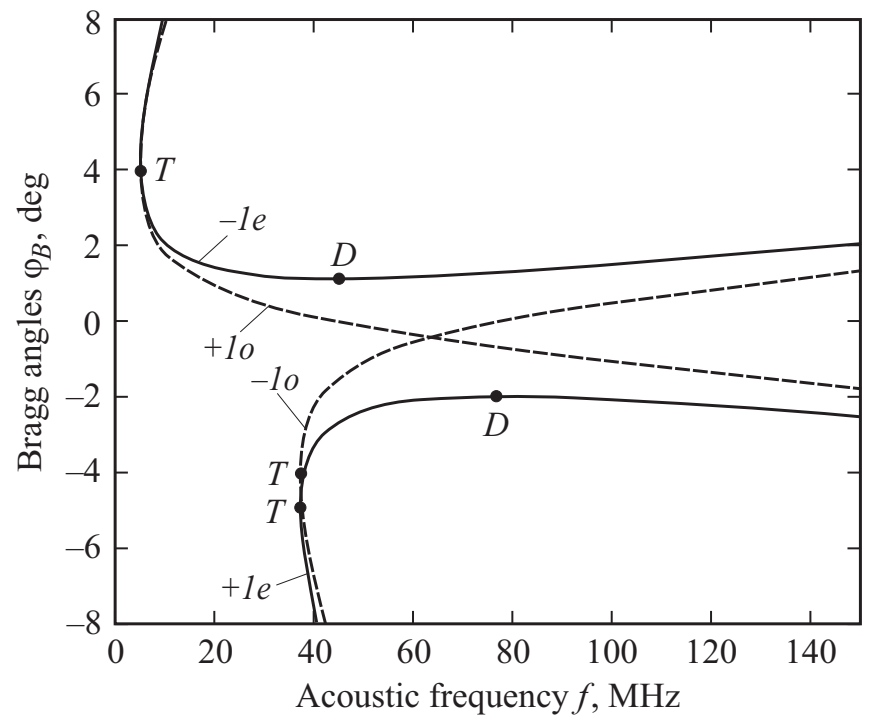

Рис. 3. Частотная зависимость углов Брэгга в кристалле парателлурита для среза $\chi=3^{\circ}$.

Выражение (11) говорит о том, что снос акустической энергии не оказывает влияния на условие фазового синхронизма. Однако выражения для $\Gamma$ и $R$ по-прежнему зависят от угла сноса $\alpha$, что означает изменение диапазона АО взаимодействия и, следовательно, угловых, частотных и спектральных характеристик [17].

\section{Результаты расчета}

Ниже представлены результаты расчета характеристик АО взаимодействия в акустическом поле, создаваемом фазированной решеткой в кристалле парателлурита. Расчет выполнен для кристаллографической плоскости (1 $\overline{1} 0)$, когда сдвиговая акустическая волна распространяется под углом $\chi=3^{\circ}$ к плоскости (001). Для этой моды скорость звука $V=0.625 \cdot 10^{5} \mathrm{~cm} / \mathrm{s}$, а угол сноса составляет $\alpha=28.3^{\circ}$. На рис. 3 показаны частотные зависимости углов Брэгга $\varphi_{\mathrm{B}}(f)$, рассчитанные для длины волны света $\lambda=0.633 \mu \mathrm{m}$. В расчете учтена оптическая активность кристалла парателлурита. Четыре кривые соответствуют разным поляризациям падающего света (обыкновенной $o$ или необыкновенной $e$ ) и рассеянию света в +1 -й или -1 -й порядки дифракции. Например, ветвь $+1 e$ характеризует дифракцию $e$-волны в +1 -й порядок. Точками $\mathrm{D}$ и Т отмечены области, оптимальные для АО дефлекторов и видеофильтров $[1,2]$.

На рис. 4 изображены области АО взаимодействия для ветви $+1 e$ в координатах $\varphi_{0}-f$. Яркость картины в каждой точке пропорциональна эффективности дифракции в первом порядке, $\zeta=\left|E_{1} / E_{i}\right|^{2}$. Горизонтальные сечения на рисунках определяют частотные характеристики взаимодействия $\xi(f)$ для выбранных углов падения света, а вертикальные сечения - угловые характеристики $\zeta\left(\varphi_{0}\right)$.
Рисунок 4,a относится к случаю однородного (т.е. несекционированного) пьезопреобразователя шириной $l=1 \mathrm{~mm}$. Форма области повторяет кривую $+1 e$ на рис. 3, а ее ширина определяется в первую очередь размером преобразователя.

В случае фазированного преобразователя с противофазным возбуждением соседних секций ситуация меняется кардинальным образом. Последующие рисунки показывают это изменение при уменьшении периода структуры $d$. В расчете количество секций $m=4$ и зазор между секциями $a=0.1 \mathrm{~mm}$.

Вначале область АО взаимодействия расщепляется на две области (рис. 4,b). При этом видны заметные отличия от варианта изотропной дифракции, представленного на рис. $1, b$, как в форме этих областей, так и в их ширине. Кроме того, появилась третья область на относительно низких частотах ультразвука, в которой также имеются точки, где выполняется условие фазового синхронизма и эффективность дифракции достигает $100 \%$. При дальнейшем уменьшении периода $d$ две левые области объединяются (рис. 4,c), и образуется совершенно необычная структура АО взаимодействия, характеризуемая низкой угловой и частотной селективностью. При еще меньшем периоде $d$ (рис. 4, $d$ ) получается три непересекающиеся области АО взаимодействия, существенно отличающиеся от варианта однородного преобразователя.

Таким образом, приведенные графики показывают, что, используя фазированные решетки преобразователей, можно получить оптимальную для создания устройств геометрию АО взаимодействия в наиболее удобном частотном диапазоне.

Особый интерес представляет случай рис. 4,c. Для оценки этого результата надо учесть, что во многих АО устройствах высокая селективность брэгговской дифракции является мешающим фактором, приводящим к уменьшению частотного и углового диапазонов взаимодействия и соответственно к ухудшению характеристик АО приборов по разрешению и быстродействию [1]. Сказанное иллюстрирует рис. 5, где показаны угловая (1) и частотная (2) характеристики, рассчитанные для $f=25 \mathrm{MHz}$ и $\varphi_{0}=-1.08^{\circ}$ соответственно. В этом случае угловой диапазон взаимодействия составляет $\Delta \varphi=5.6^{\circ}$, а частотный диапазон $-\Delta f=76 \mathrm{MHz}$. Таким образом, с помощью одной и той же АО ячейки можно в широком частотном диапазоне обрабатывать как коллимированные световые пучки, так и пучки, несущие изображение.

Еще один интересный вариант АО взаимодействия, принципиально невозможный при дифракции в однородном акустическом поле, иллюстрирует рис. 6, на котором представлены частотные зависимости оптимальных углов падения $\varphi_{\text {opt }}$, совмещенные для ветвей $+1 e$ и $+1 o$. Расчет выполнен для $m=4$ и $l=0.2 \mathrm{~mm}$. Из рисунка видно, что кривые, относящиеся к разным дифракционным порядкам $+1 e$ и $+1 o$, пересекаются в точке $\mathrm{M}$ на частоте $f=142 \mathrm{MHz}$. Это означает, что 

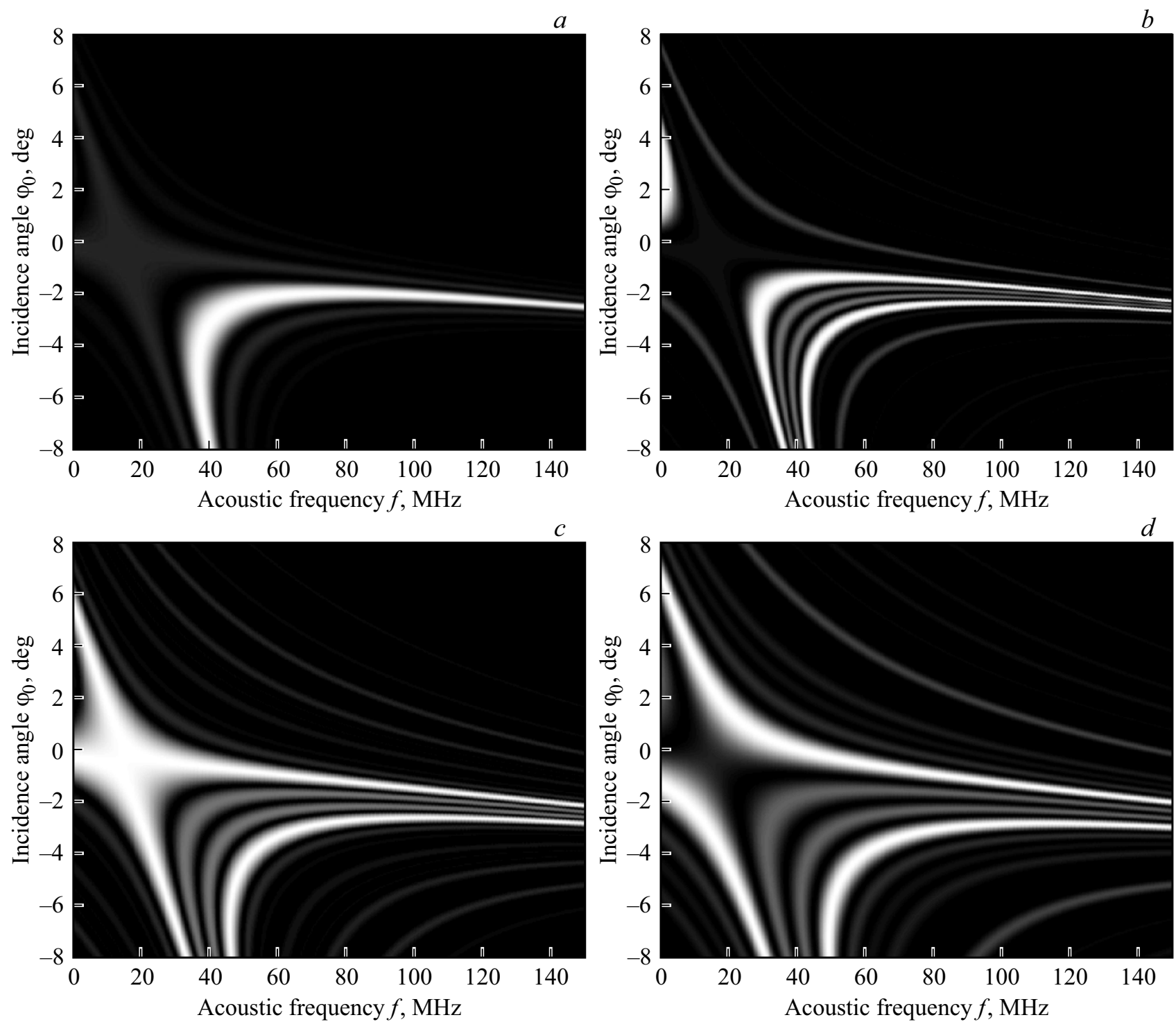

Рис. 4. Области $\mathrm{AO}$ взаимодействия для ветви $+1 e$. Расчет выполнен для разных значений ширины акустического столба: $l=1(a)$, $0.5(b), 0.25(c)$ и $0.15 \mathrm{~mm}(d)$.

на указанной частоте световые волны с обыкновенной и необыкновенной поляризациями должны рассеиваться в один и тот же дифракционный максимум +1 -го порядка. Такая геометрия АО взаимодействия позволяет модулировать интенсивность неполяризованных световых пучков. В этой связи следует отметить, что проблема АО модуляции неполяризованного света существует с начала 60-х годов прошлого столетия и пока не получила эффективного решения. Наиболее простой путь - это поиск срезов кристаллов с близкими значениями АО качества для обеих оптических мод. Подходящим материалом является молибдат свинца $\left(\mathrm{PbMoO}_{4}\right)$ [18]. Однако он характеризуется относительно небольшим значением АО качества $M=36 \cdot 10^{-18} \mathrm{~s}^{3} / \mathrm{g}$ и, главное, имеет плохие термофизические свойства. Серийно выпускаются модуляторы из парателлурита с продольной акустической волной вдоль оси $Z$, но этот срез кристалла характеризуется заметным различием коэффициентов качества для $o$ - и $e$-волн: $M_{o}=30 \cdot 10^{-18} \mathrm{~s}^{3} / \mathrm{g}$ и $M_{e}=22 \cdot 10^{-18} \mathrm{~s}^{3} / \mathrm{g}$. Можно также отметить предложенную в работе [19] экзотическую схему модулятора с двумя разнонаправленными акустическими пучками, имеющими разные частоты. В предлагаемом нами существенно более простом варианте модулятора на кристалле парателлурита с фазированным пьезопреобразователем коэффициенты качества для обеих оптических мод одинаковые (вследствие анизотропного типа дифракции) и равны $M=1130 \cdot 10^{-18} \mathrm{~s}^{3} / \mathrm{g}$. Положение рабочей точки М определяется периодом структуры преобразователя: варьируя ширину акустических пучков $l$ от 0.23 до $0.16 \mathrm{~mm}$, можно менять рабочую частоту в широком 


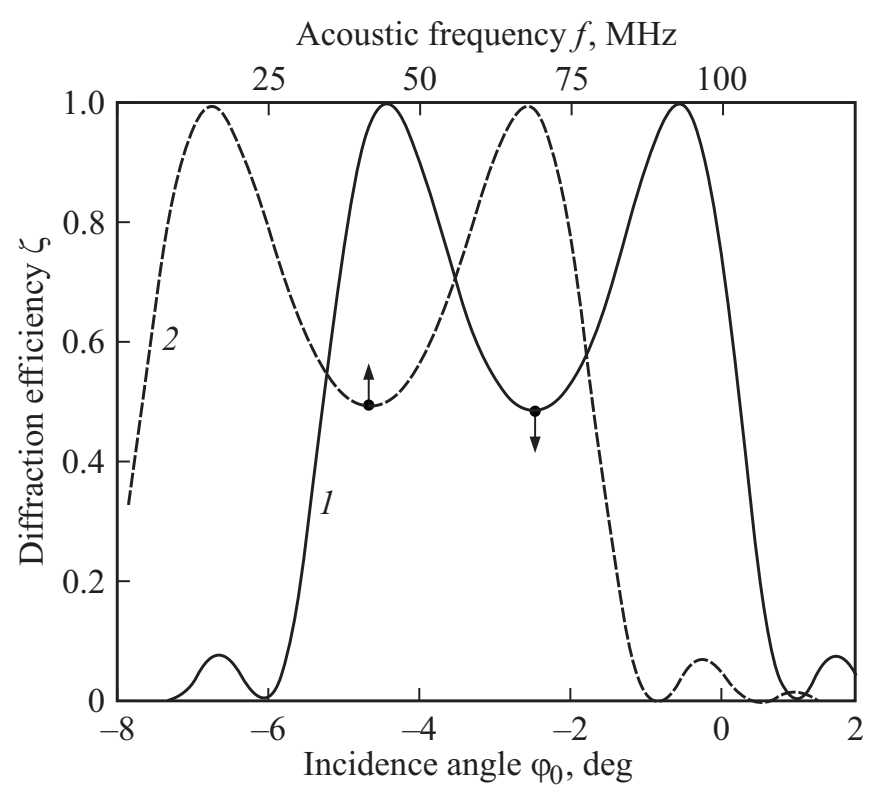

Рис. 5. УГловая (1) и частотная (2) характеристики АО взаимодействия для варианта, представленного на рис. $4, c$.

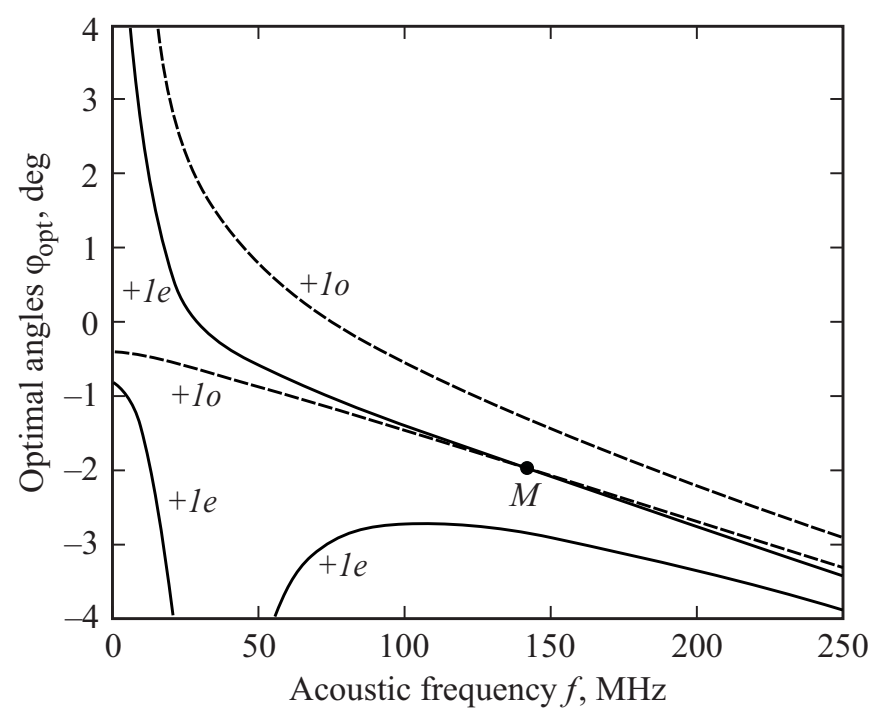

Рис. 6. Оптимальные углы падения света для ветвей $+1 e$ и $+1 o$ анизотропной дифракции. Расчет выполнен для $\chi=3^{\circ}$, $m=4$ и $l=0.2 \mathrm{~mm}$.

диапазоне от 70 до $193 \mathrm{MHz}$. Аналогичные варианты модулятора возможны и для других срезов кристалла парателлурита.

\section{Заключение}

В работе представлены результаты теоретического исследования анизотропной брэгговской дифракции света в пространственно периодическом акустическом поле, создаваемом секционированным пьезопреобразователем с противофазным возбуждением соседних секций. Чис- ленные расчеты выполнены для АО ячейки из кристалла парателлурита со сдвиговой акустической модой, распространяющейся под углом $\chi=3^{\circ}$ к плоскости (001) кристалла. Показано, что в такой структуре АО взаимодействие отсутствует при падении света под углом Брэгга. Однако существуют углы падения, названные „оптимальными“, при которых эффективность дифракции может достигать 100\%, несмотря на нарушение условия фазового синхронизма. Рассчитаны области АО взаимодействия для разных периодов структуры преобразователя. Установлен ряд необычных закономерностей АО рассеяния света, которые могут быть полезны при разработке АО устройств нового типа. В частности, показана возможность реализации модулятора неполяризованного света с существенно лучшими характеристиками, чем у известных в настоящее время устройств.

\section{Финансирование работы}

Работа выполнена при финансовой поддержке Российского фонда фундаментальных исследований (РФФИ), грант № 17-07-00369.

\section{Конфликт интересов}

Авторы заявляют, что у них нет конфликта интересов.

\section{Список литературы}

[1] Балакший В.И., Парыгин В.Н., Чирков Л.Е. Физические основы акустооптики. М.: Радио и связь, 1985.

[2] Xu J., Stroud R. Acousto-optic Devices: Principles, Design, and Applications. NY.: Wiley, 1992.

[3] Задорин А.С. Динамика акустооптического взаимодействия. Томск: ТГУ, 2004.

[4] Korpel A., Adler R., Desmares P., Watson W. // Proc. IEEE. 1966. V. 54. N 10. P. 1429. doi 10.1109/PROC.1966.5129

[5] Coquin G.A., Griffin J.P., Anderson L.K. // IEEE Trans. Son. Ultrason. 1970. V. SU-17. N 1. P. 34. doi 10.1109/TSU.1970.29542

[6] Alphonse G.A. // Appl. Opt. 1975. V. 14. N 1. P. 201. doi 10.1364/AO.14.000201

[7] Kim S., Gao L., Wagner K., Weverka R., McLeod R. // Proc. SPIE. 2005. V. 5953. P. 59530M. doi $10.1117 / 12.622623$

[8] Антонов С.Н., Вайнер А.В., Проклов В.В., Резвов Ю.Г. // ЖТФ. 2013. Т. 83. № 9. С. 108. doi 10.1134/S1063784213090053

[9] Balakshy V.I., Linde B.B.J., Vostrikova A.N. // Ultrasonics. 2008. V. 48. N 5. P. 351. doi 10.1016/j.ultras.2008.01.001

[10] Манцевич С.Н., Балакший В.И. // Опт. и спектр. 2015. T. 118. № 4. C. 646. doi 10.7868/S0030403415040157

[11] Dixon R.W. // IEEE J. Quant. El. 1967. V. QE-3. N 2. P. 85. doi 10.1109/JQE.1967.1074447

[12] Voloshin A., Balakshy V., Mantsevich S. // Proc. 2016 IEEE Int. Ultrasonics Symp., Tours (France). 2016. P. 767. doi 10.1109/ULTSYM.2016.7728646

[13] Пожсар В.Э., Пустовойт В.И. // Успехи соврем. радиоэлектрон. 2006. № 9. С. 61. 
[14] Балакший В.И., Волошин А.С. // Опт. и спектр. 2011. T. 110. № 5. C. 840 . doi 10.1134/S0030400X11050031

[15] Балакший В.И., Волошин А.С., Молчанов В.Я. // Опт. и спектр. 2014. Т. 117. № 5. С. 827. doi 10.7868/S003040341411004X

[16] Пожсар В.Э., Пустовойт В.И. // Квант. электрон. 1985. T. 12. № 10. C. 2180.

[17] Balakshy V.I., Voloshin A.S., Molchanov V.Ya. // Ultrasonics. 2015. V. 59. P. 102. doi 10.1016/j.ultras.2015.02.002

[18] Pinnow D.A., Van Uitert L.G., Warner A.W., Bonner W.A. // Appl. Phys. Lett. 1969. V. 15. N 3. P. 83. doi $10.1063 / 1.1652917$

[19] Антонов С.Н., Миргородский В.И. // ЖТФ. 2004. Т. 74. № 1. C. 84 . doi 10.1134/1.1642684 